\title{
Estimation of Effective Dose from External Exposure in The Six Prefectures adjacent to Fukushima Prefecture
}

\author{
Hirokazu Miyatake ${ }^{1, a}$, Nobuaki Yoshizawa ${ }^{1}$, Sachiko Hirakawa ${ }^{1}$, Kana Murakami $^{1}$, Mari Takizawa ${ }^{1}$, Masaki Kawai $^{1}$, Osamu Sato $^{1}$, Shunji \\ Takagi $^{1}$ and Gen Suzuki ${ }^{2}$
}

${ }^{I}$ Mitsubishi Research Institute, Inc.: 2-10-3, Nagata-cho, Chiyoda-ku, Tokyo, Japan

${ }^{2}$ International University of Health and Welfare Clinic: 2600-6, Kitakanemaru, Otawara-city, Tochigi, Japan

\begin{abstract}
The Fukushima Daiichi Nuclear Power Plant accident caused a release of radionuclides. Radionuclides were deposited on the ground not only in Fukushima prefecture but also in nearby prefectures. Since the accident, measurement of radiation in environment such as air dose rate and deposition density of radionuclides has been performed by many organizations and universities. In particular, Japan Atomic Energy Agency (JAEA) has been performing observations of air dose rate using a car-borne survey system continuously and over wide areas. In our study, using the data measured by JAEA, we estimated effective dose from external exposure in the six prefectures adjacent to Fukushima prefecture. Since car-borne survey was started a few months later after the accident, measured air dose rate in this method is mainly contributed by ${ }^{137} \mathrm{Cs}$ and ${ }^{134} \mathrm{Cs}$ whose half-lives are relatively long. Therefore, based on air dose rate of ${ }^{137} \mathrm{Cs}$ and ${ }^{134} \mathrm{Cs}$ and the ratio of deposition density of short-half-life nuclides to that of ${ }^{137} \mathrm{Cs}$ and ${ }^{134} \mathrm{Cs}$, we also estimated effective dose contributed from not only ${ }^{137} \mathrm{Cs}$ and ${ }^{134} \mathrm{Cs}$ but also other short-halflife nuclides. We compared the effective dose estimated by the method above with that of UNSCEAR and measured data using personal dosimeters in some areas.
\end{abstract}

\section{Introduction}

The Fukushima Daiichi Nuclear Power Plant accident caused a release of radionuclides. Radionuclides were deposited on the ground not only in Fukushima prefecture but also in nearby prefectures. Since the accident, measurement of radiation in environment such as air dose rate and deposition density of radionuclides has been performed by many organizations and universities. In particular, Japan Atomic Energy Agency (JAEA) has been performing observations of air dose rate using a car-borne survey system continuously and over wide areas. There has been 11 times surveys performed as of March 2016 [1].

In our study, considering some factors such as time spent indoor and outdoor, background and radiation reduction by house, and using the data of air dose rate measured by JAEA [2], we estimated effective dose from external exposure in the six prefectures adjacent to Fukushima prefecture (Iwate pref., Miyagi pref., Ibaraki pref., Tochigi pref., Gunma Pref. and Chiba Pref.).

United Nations Scientific Committee on the Effects of Atomic Radiation has also estimated effective dose using measured date of radiation in environment [3]. In their method, density of radionuclides is used. There is a similarity between UNSCEAR's method and ours in terms of using measured data in environment. However, although the data that we use has been measured continuously, the data that UNSCEAR used was the one that was measured only one time.
There is also another approach such as measurement using personal dosimeters. This kind of survey was performed some places, such as Tochigi pref., Kashiwa city in Chba pref. and Marumori town in Miyagi pref [4] [5] [6].

In the case of Marumori town in Miyagi pref., this town was divided into three areas (Area-A,B,C) and measurement of external dose was performed using personal dosimeter. There were a few hundred children as examinee, and the measurement had been continued for two years since September 2011. In this survey, other data such as time spent indoor and outdoor, body height and bodily weight. In the relevant survey, radiation reduction factor of typical types of house in the nearby areas was also measured [7]. For purpose of reference, typical measured data are shown in the Table. 1 for three areas.

Table. 1. Typical measured data of dose from external exposure of children in Marumori town in Miyagi pref. [5]

\begin{tabular}{|c|c|c|}
\hline & Measurement period & Result \\
\hline Area-A & $2011.12 \sim 2012.9$ & $2.25 \mathrm{mSv}$ \\
\hline Area-B & $2012.6 \sim 2013.11$ & $1.63 \mathrm{mSv}$ \\
\hline Area-C & $2012.7 \sim 2013.11$ & $1.26 \mathrm{mSv}$ \\
\hline
\end{tabular}

Measurement using personal dosimeter has the advantage that the date measured contains various sorts of uncertainties such as time spend indoor and outdoor and type of houses, therefore it is not necessary to

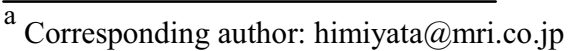


introduce any conversion coefficients or assumptions. On the other hand, examinees have to attach dosimeters to their bodies, and therefore it is difficult to keep measuring for years against many examinees.

In our study, we estimated effective dose from external exposure based on measured air dose rate by car-borne survey by JAEA, and compered its vale to the one estimated by UNSCEAR and the one measured using personal dosimeters in Marumori town in Miyagi Pref.

\section{Methods}

In our study, we annualized measured air dose rate with two models. By fitting with the models, timedependent function of air dose rate. Maltiplying some conversion factors and subtracting background, air dose rate can be converted to effective dose rate contributed from nuclides that were released by The Fukushima Daiichi Nuclear Power Plant accident. Integrating this, accumulative effective dose from external exposure can be obtained (See Fig. 1).

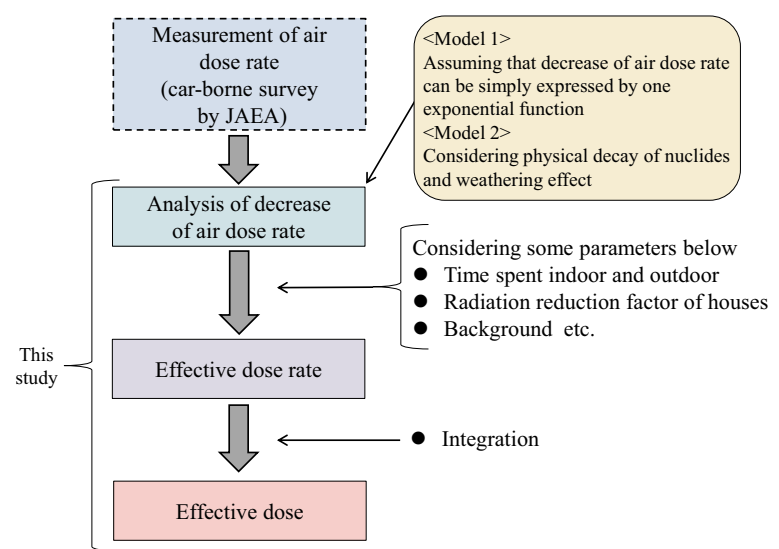

Fig. 1. Estimation flow of this study

\subsection{Models of decrease of air does rate}

Air dose rate decreases because of physical decay and weathering effect. In the case of physical decay, air dose rate decay at the pace determined by half-life of each nuclide. Weathering effect is a natural phenomenon where rainfall promotes nuclide to penetrate into the soil, therefore this depends on weather condition or soil characteristics of each area.

In this study, we use two models to analyze decrease of air dose rate. The first model is given by the equation (1). In this model, it is assumed that decrease of air dose rate can be simply expressed by one exponential function.

$$
D_{\text {air }}(t)=a \exp (-b t)+c
$$

The second model is given by the equation (2) using the parameters listed in the Table. 2 [8]. In this model, decay of nuclide and weathering are considered.

$$
\begin{aligned}
D_{\text {air }}(t) & =\left(D_{0}-D_{\mathrm{BG}}\right) \\
\times & \left\{f_{\text {fast }} \exp \left(-\frac{0.693}{T_{\text {fast }}} t\right)+\left(1-f_{\text {fast }}\right) \exp \left(-\frac{0.693}{T_{\text {slow }}} t\right)\right\} \\
\times & \frac{k \exp \left(-\lambda_{134} t\right)+\exp \left(-\lambda_{137} t\right)}{k+1}+D_{\mathrm{BG}}
\end{aligned}
$$

According to the previous studies, weathering effect can be expressed as the second term in equation (2) under the assumption that this effect can be divided into two elements whose contributions are normalized, where $f_{\text {fast }}$ is fraction of fast element, and $T_{\text {fast }}$ and $T_{\text {slow }}$ are half-life of fast and slow elements [9]. The third term in equation (2) coresponds to physical decay of ${ }^{137} \mathrm{Cs}$ and ${ }^{134} \mathrm{Cs}$, where $k$ is ratio of ${ }^{137} \mathrm{Cs}$ to ${ }^{134} \mathrm{Cs}$ contributing to air dose under the assumption that the initial value of deposition density of each nuclide is same, and $\lambda_{134}$ and $\lambda_{137}$ are decay constants of each nuclide.

Table. 2. Parameters in the second model

\begin{tabular}{|c|l|}
\hline \multicolumn{2}{|c|}{ Parameters } \\
\hline$D_{0}$ & Initial value of air dose rate $(\mu \mathrm{Sv} / \mathrm{h})$ \\
\hline$D_{\mathrm{BG}}$ & Background $(\mu \mathrm{Sv} / \mathrm{h})$ \\
\hline$f_{\text {fast }}$ & $\begin{array}{l}\text { Fraction of fast element of weathering } \\
\text { effect (dimensionless) }\end{array}$ \\
\hline$T_{\text {fast }}$ & $\begin{array}{l}\text { Half-life of fast element of weathering } \\
\text { effect (y) }\end{array}$ \\
\hline$T_{\text {slow }}$ & $\begin{array}{l}\text { Half-life of slow element of weathering } \\
\text { effect (y) }\end{array}$ \\
\hline$k$ & $\begin{array}{l}\text { Ratio of }{ }^{137} \mathrm{Cs} \text { to }{ }^{134} \mathrm{Cs} \text { contributing to air } \\
\text { dose (dimensionless) }\end{array}$ \\
\hline$\lambda_{134}, \lambda_{137}$ & Decay constant of ${ }^{134} \mathrm{Cs}$ and ${ }^{137} \mathrm{Cs}(1 / \mathrm{y})$ \\
\hline
\end{tabular}

\subsection{Conversion to effective dose}

Considering some factors such as time spent indoor and outdoor, background and radiation reduction of houses, air dose rate can be converted to effective dose rate as shown in equation (3). In this study, by substracting the background which was measured in the area of interest before the accident, we estimated the dose added by the nulides released by The Fukushima Daiichi Nuclear Power Plant accident the accident.

$$
\frac{d E(t)}{d t}=\left(p D_{\text {air }}(t)-D_{\mathrm{BG}}\right) \times\left(s T_{\text {in }}+T_{\text {out }}\right) \times \alpha \times f
$$

In car-borne survey, measurement is conducted on streets with detectors set in the car. The measured air dose rate is the one on streets. Because of traffics of cars, nuclides deposited on streets are easier to be removed or penetrate into soil than in living environment, therefore air dose rate measured by car-borne survey tends to be smaller air dose rate measured in living environment. It is shown that the former is approximately 1.2 times lareger than the latter by man-borne survey conducted nearby the street where car-borne surevy was also conducted [10]. Considering this difference, the coefficient $p$ is multiplied by $D_{\text {air }}(t)$.

Air dose rate $D_{\text {air }}(t)$ includes background. By subtracting background $D_{\mathrm{BG}}$, the net contribution from nuclides released by The Fukushima Daiichi Nuclear 
Power Plant accident is only considered. As background $D_{\mathrm{BG}}$, we used the measured data in prefectural capitals of each prefecture before the accident (Table. 3) [11].

Table. 3. Background in prefectural capitals of each prefecture

\begin{tabular}{|c|c|}
\hline Prefecture & $D_{\mathrm{BG}}(\mu \mathrm{Sv} / \mathrm{h})$ \\
\hline Iwate pref. & 0.062 \\
\hline Miyagi pref. & 0.066 \\
\hline Ibaraki pref. & 0.063 \\
\hline Tochigi pref. & 0.055 \\
\hline Gunma pref. & 0.065 \\
\hline Chiba pref. & 0.059 \\
\hline
\end{tabular}

After The Fukushima Daiichi Nuclear Power Plant accident, there was a statistical survey on time spent indoor and outdoor of Fukushima City office workers [12]. According to this, indoor workers spend 0.57 hours outdoor on average. In this study, although the targeted prefectures are not Fukushima prefecture, we used this value.

Radiations are reduced indoor because of shielding effect of houses. In this study, we adapted the value 0.4 for reduction factor $s$ [13].

For conversion factor between air dose rate and effective dose, we adapted the value 0.6 , where the target that we estimate is assumed to be adult [14].

Table. 4. Paremeters to conver frome air dose rate to effective dose rate.

\begin{tabular}{|c|l|}
\hline \multicolumn{2}{|c|}{ Parameters } \\
\hline$p$ & $\begin{array}{l}\text { Ratio of air dose rate in living atmosphere to } \\
\text { that on streets }(1.2)\end{array}$ \\
\hline$D_{\mathrm{BG}}$ & Background (see Table. 3) \\
\hline$s$ & Radiation reduction factor $(0.4)$ \\
\hline$T_{\text {in }}$ & Time spent indoor $(23.43 \mathrm{~h} / \mathrm{d})$ \\
\hline$T_{\text {out }}$ & Time spent outdoor $(0.57 \mathrm{~h} / \mathrm{d})$ \\
\hline$\alpha$ & Number of days per year $(365 \mathrm{~h} / \mathrm{d})$ \\
\hline$f$ & $\begin{array}{l}\text { Conversion factor between air dose rate and } \\
\text { effective dose }(0.6)\end{array}$ \\
\hline
\end{tabular}

Finaly, by integrating according to equation (3), accumulated effective dose in the period (form year $T_{1}$ to $T_{2}$ ) can be estimated.

$$
E\left(T_{1}, T_{2}\right)=\int_{T_{1}}^{T_{2}} \frac{d E(t)}{d t} d t
$$

\subsection{Effective dose considering short-half-life nuclides}

Since car-borne survey was started a few months later after the accident, measured air dose rate in this method is mainly contributed by ${ }^{137} \mathrm{Cs}$ and ${ }^{134} \mathrm{Cs}$ whose half-lives are relatively long. Therefore, based on air dose rate of ${ }^{137} \mathrm{Cs}$ and ${ }^{134} \mathrm{Cs}$ and the ratio of deposition density of short-half-life nuclides to that of ${ }^{137} \mathrm{Cs}$ and ${ }^{134} \mathrm{Cs}$, we also estimated effective dose contributed from not only ${ }^{137} \mathrm{Cs}$ and ${ }^{134} \mathrm{Cs}$ but also other short-half-life nuclides.

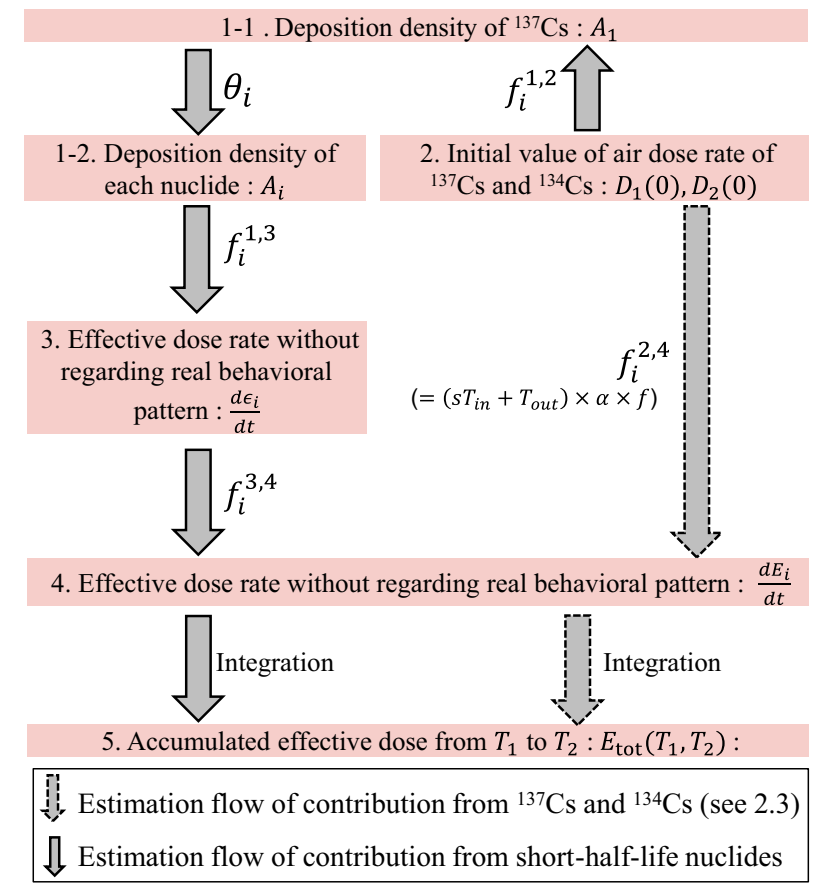

Fig. 2. Estimation flow of contribution of short-halflife nuclides

The initial value $D_{\text {air }}(0)$ can be obtained by plugging in 0 into $t$ in eqution (1) or (2). This value can be considerd as sum of the contribution of ${ }^{137} \mathrm{Cs},{ }^{134} \mathrm{Cs}$ and background as shown in equation (5).

$$
D_{\text {air }}(0)=D_{1}(0)+D_{2}(0)+D_{\mathrm{BG}}
$$

Where $D_{1}(0)$ is air dose rate contributed from ${ }^{137} \mathrm{Cs}$ in the soil and $D_{2}(0)$ is that of ${ }^{134} \mathrm{Cs}$ in the soil. As shown in the Table. 5, index $i$ is defined to indicate each nuclide. Index $i=1,2$ correspond ${ }^{137} \mathrm{Cs}$ and ${ }^{134} \mathrm{Cs}$. By substructing back ground from $D_{\text {air }}(0)$, value $D_{1}(0)+D_{2}(0)$ can be obtained.

By defining deposition density for each nuclide $i$ as $A_{i}$ and conversion factor from deposition density $A_{i}$ to air dose rate as $f_{i}^{1,2}$, for ${ }^{137} \mathrm{Cs}(i=1)$ and ${ }^{134} \mathrm{Cs}$ ( $i=2)$, the equation below is obtained.

$$
D_{1}(0)+D_{2}(0)=f_{1}^{1,2} A_{1}+f_{2}^{1,2} A_{2}
$$

Assumuing that the initial value of deposition densityof ${ }^{137} \mathrm{Cs}$ and ${ }^{134} \mathrm{Cs}$ is same $\left(A_{1}=A_{2}\right)$ [15], parameter $A_{2}$ can be eliminated, then the equation below is obtained.

$$
A_{1}=\frac{D_{1}(0)+D_{2}(0)}{f_{1}^{1,2}+f_{2}^{1,2}}
$$

Defining the ratio of initial deposition density of each nuclide $i$ to that of ${ }^{137} \mathrm{Cs}(i=1)$ as $\vartheta_{i}$, the equation below can be obtained.

$$
A_{i}=\vartheta_{i} A_{1}
$$

Although this ratio has been studied in many previous studies, in this study, we adapted the same values as UNSCEAR (Table. 5) [15]. 
Table. 5. Deposition ratio and half-life for each nuclide $i$

\begin{tabular}{|c|c|c|c|}
\hline$i$ & Nuclide & $\vartheta_{i}$ & $T_{i}^{\text {half }}$ \\
\hline 1 & ${ }^{137} \mathrm{Cs}+{ }^{137 \mathrm{~m}} \mathrm{Ba}$ & - & $30 \mathrm{y}$ \\
\hline 2 & ${ }^{134} \mathrm{Cs}$ & 1.0 & $2.1 \mathrm{y}$ \\
\hline 3 & ${ }^{136} \mathrm{Cs}$ & 0.17 & $13 \mathrm{~d}$ \\
\hline 4 & ${ }^{131} \mathrm{I}$ & 12 & $8.0 \mathrm{~d}$ \\
\hline 5 & ${ }^{129 \mathrm{~m}+129} \mathrm{Te}$ & 1.1 & $34 \mathrm{~d}$ \\
\hline 6 & ${ }^{132} \mathrm{Te}+{ }^{132} \mathrm{I}$ & 8.0 & $3.2 \mathrm{~d}$ \\
\hline 7 & ${ }^{110 \mathrm{~m}+110} \mathrm{Ag}$ & $2.8 \times 10^{-3}$ & $25 \mathrm{~d}$ \\
\hline
\end{tabular}

Defining the conversion factor from deoisition density $A_{i}$ to effective dose rate $d \varepsilon_{i} / d t$ as $f_{i}^{1,3}$, effective dose ration contributed from each nuclide $i$ can be expressed as the equation (9), where $T_{i}^{\text {half }}$ is half-life for nuclide $i$.

$$
\frac{d \varepsilon_{i}(t)}{d t}=A_{i} \exp \left(-\frac{\ln 2}{T_{i}^{\text {half }}} t\right)
$$

As shown in 2.2, by multiplying some factors (defining its product as $f_{i}^{3,4}$ in equation (10)),

$$
f_{i}^{3,4}=\left(s T_{\text {in }}+T_{\text {out }}\right) \times \alpha
$$

this can be converted to effective dose that considers time spent indoor and outdoor, and reduction factor is obtained as shown in equation (11).

$$
\frac{d E_{i}(t)}{d t}=f_{i}^{3,4} \frac{d \varepsilon_{i}(t)}{d t}
$$

Finally, by integrating equation (11), accumulated effective dose including short-half-life nucliide can be obtained.

$$
E_{\mathrm{tot}}\left(T_{1}, T_{2}\right)=E\left(T_{1}, T_{2}\right)+\sum_{i=3}^{7} \int_{T_{1}}^{T_{2}} \frac{d E_{i}(t)}{d t} d t
$$

Since effective dose contributed from ${ }^{137} \mathrm{Cs}$ and ${ }^{134} \mathrm{Cs}$ $\left(E\left(T_{1}, T_{2}\right)\right)$ can be obtaind in the way expressed in 2.2, the total effective dose is expresserd, the second term in equation (12) is expressed as the sam from $i=3$ to $i=7$.

Table. 6. Conversion factor $f_{i}^{1,2}$ and $f_{i}^{1,3}[15][16]$

\begin{tabular}{|c|c|c|c|}
\hline \multirow{2}{*}{$i$} & \multirow{2}{*}{ Nuclide } & $f_{i}^{1,2}$ & $f_{i}^{1,3}$ \\
\cline { 3 - 4 } & & \multicolumn{2}{|c|}{$\left(\times 10^{-3} \mu \mathrm{Sv} / \mathrm{h} \mathrm{per} \mathrm{kBq} / \mathrm{m}^{2}\right)$} \\
\hline 1 & ${ }^{137} \mathrm{Cs}+{ }^{137 \mathrm{~m}} \mathrm{Ba}$ & 2.3 & - \\
\hline 2 & ${ }^{134} \mathrm{Cs}$ & 6.3 & - \\
\hline 3 & ${ }^{136} \mathrm{Cs}$ & - & 4.7 \\
\hline 4 & ${ }^{131} \mathrm{I}$ & - & 0.85 \\
\hline 5 & ${ }^{129 \mathrm{~m}+129} \mathrm{Te}$ & - & 0.15 \\
\hline 6 & ${ }^{132} \mathrm{Te}^{132} \mathrm{I}$ & - & 5.5 \\
\hline 7 & ${ }^{110 \mathrm{~m}+110} \mathrm{Ag}$ & - & 6.1 \\
\hline
\end{tabular}

\section{Results}

3.1 Time-dependent degrease of air dose rate

By fitting the average of measured data of air dose rate from the first the 7th car-borne survey with the two models shown in 2.1, we analysed time-dependent degrease of air dose rate in the 6 prefectures (Iwate pref., Miyagi pref., Ibaraki pref., Tochigi pref., Gunma Pref. and Chiba Pref.).

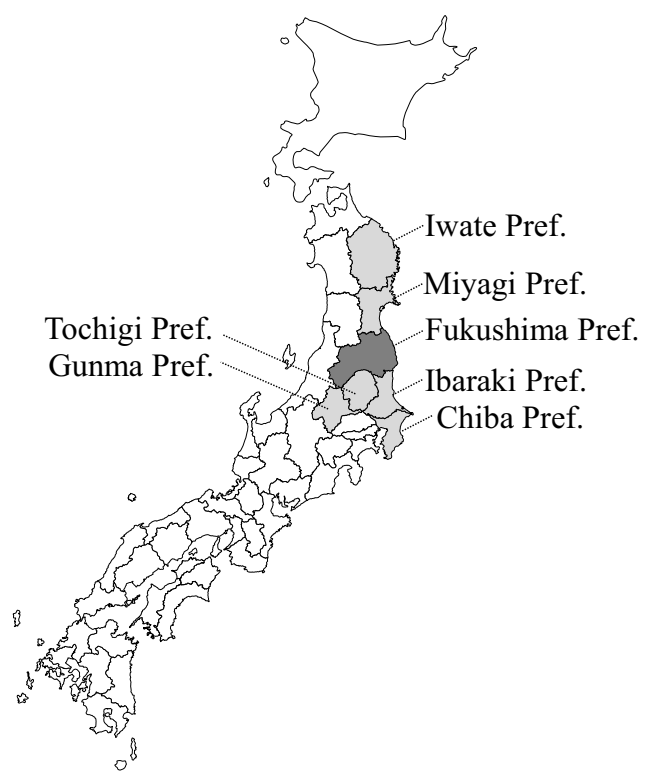

Fig. 3. Prefectures targeted in this study

In the first model, parameters $a, b$ and $c$ were free. In the second model, $D_{0}, f_{\text {fast }}$ and $T_{\text {fast }}$ were free, although $T_{\text {slow }}$ was constan $\left(T_{\text {slow }}=92\right.$ y $)$ [7] and as $D_{\mathrm{BG}}$ the values in the Table. 3 were used.

The parameters for Miyagi Pref., Tochigi Pref. and Ibaraki Pref. were derermined by fitting as shown in the Table. 7 and Table. 8. For the three prefectures (Miyagi, Ibraki and Tochigi Pref.), averaged measured data and time-dependent degrease of air dose rate drawn by the determined parameters are shown in Fig. $4 \sim$ Fig. 6 .

Table. 7. Fitting paremeters for the first model (Miyagi, Ibraki and Tochigi Pref.)

\begin{tabular}{|c|c|c|c|}
\hline & $a(\mu \mathrm{Sv} / \mathrm{h})$ & $b(1 / \mathrm{y})$ & $c(\mu \mathrm{Sv} / \mathrm{h})$ \\
\hline $\begin{array}{c}\text { Miyagi } \\
\text { Pref. }\end{array}$ & 0.48 & 3.0 & 0.075 \\
\hline $\begin{array}{c}\text { Ibaraki } \\
\text { Pref. }\end{array}$ & 0.21 & 2.3 & 0.093 \\
\hline $\begin{array}{c}\text { Tochigi } \\
\text { Pref. }\end{array}$ & 0.47 & 2.9 & 0.096 \\
\hline
\end{tabular}

Table. 8. Fitting paremeters for the second model (Miyagi Pref., Ibraki Pref. and Tochigi Pref.)

\begin{tabular}{|c|c|c|c|}
\hline & $D_{0}(\mu \mathrm{Sv} / \mathrm{h})$ & $f_{\text {fast }}$ & $T_{\text {fast }}(1 / \mathrm{y})$ \\
\hline $\begin{array}{c}\text { Miyagi } \\
\text { Pref. }\end{array}$ & 0.58 & 0.97 & 3.0 \\
\hline $\begin{array}{c}\text { Ibaraki } \\
\text { Pref. }\end{array}$ & 0.32 & 0.82 & 2.5 \\
\hline $\begin{array}{c}\text { Tochigi } \\
\text { Pref. }\end{array}$ & 0.59 & 0.88 & 3.1 \\
\hline
\end{tabular}




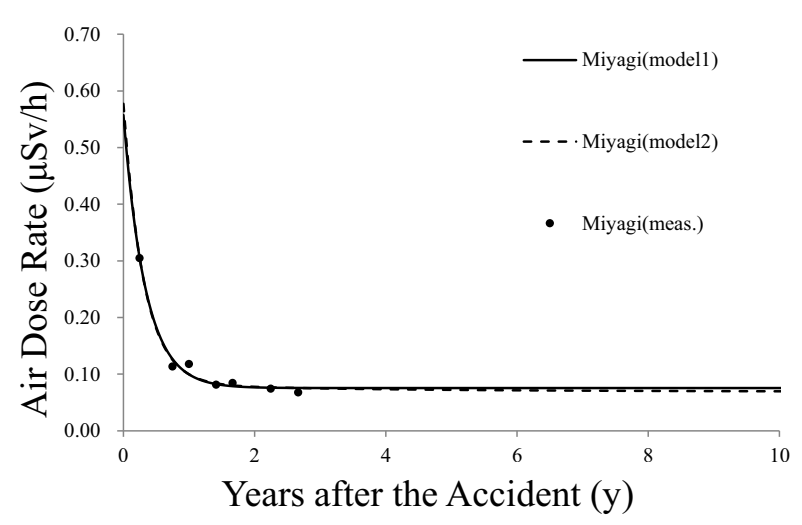

Fig. 4. Air does rate (Miyagi Pref.)

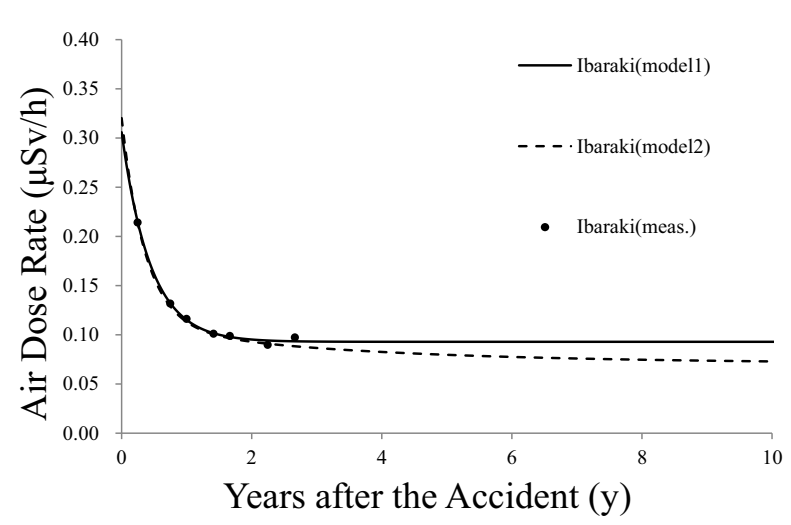

Fig. 5. Air does rate (Ibaralki Pref.)

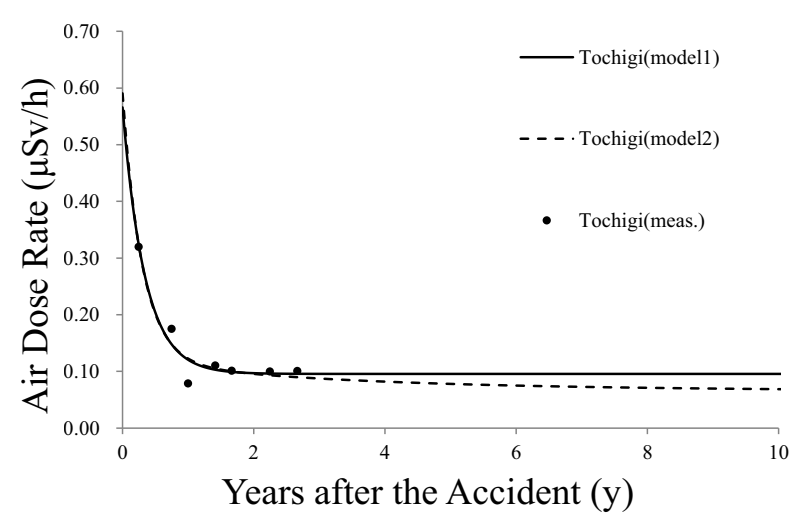

Fig. 6. Air does rate (Tochigi Pref.)

In the three prefectures (Miyagi, Ibraki and Tochigi Pref.) where measured data of air dose rate were relatively small, there were some cases where fitting parameters were not determined appropriately. In order to avoid this, we used the fitting parameters in the other prefecture ( $b$ in the first model, and $T_{\text {fast }}$ in the second model) and fixed the parameter ( $f_{\text {fast }}$ in the second model). The parameters determined for these three prefectures are shown in Table. 9 and Table. 10.
Table. 9. Fitting paremeters for the first model (Iwate, Gunma and Chiba Pref.)

\begin{tabular}{|c|c|c|c|}
\hline & $a(\mu \mathrm{Sv} / \mathrm{h})$ & $b(1 / \mathrm{y})$ & $c(\mu \mathrm{Sv} / \mathrm{h})$ \\
\hline $\begin{array}{c}\text { Iwate } \\
\text { Pref. }\end{array}$ & 0.17 & $0.81^{* 1}$ & 0.030 \\
\hline $\begin{array}{c}\text { Gunma } \\
\text { Pref. }\end{array}$ & 0.089 & 0.81 & 0.051 \\
\hline $\begin{array}{c}\text { Chiba } \\
\text { Pref. }\end{array}$ & 0.13 & $0.81^{* 1}$ & 0.053 \\
\hline
\end{tabular}

*1 Using the parameter determined in Gunma Pref.

Table. 10. Fitting paremeters for the second model (Iwate, Gunma and Chiba Pref.)

\begin{tabular}{|c|c|c|c|}
\hline & $D_{0}(\mu \mathrm{Sv} / \mathrm{h})$ & $f_{\text {fast }}$ & $T_{\text {fast }}(1 / \mathrm{y})$ \\
\hline $\begin{array}{c}\text { Iwate } \\
\text { Pref. }\end{array}$ & 0.20 & $0.90^{* 2}$ & $1.3^{* 3}$ \\
\hline $\begin{array}{c}\text { Gunma } \\
\text { Pref. }\end{array}$ & 0.15 & $0.90^{* 2}$ & 1.3 \\
\hline $\begin{array}{c}\text { Chiba } \\
\text { Pref. }\end{array}$ & 0.24 & $0.90^{* 2}$ & $1.3^{* 3}$ \\
\hline
\end{tabular}

$* 2$ Fixed with the typical value

*3 Using the parameter determined in Gunma Pref.

Averaged measured data and time-dependent degrease of air dose rate drawn by the determined parameters are shown in Fig. 7 Fig. 9.

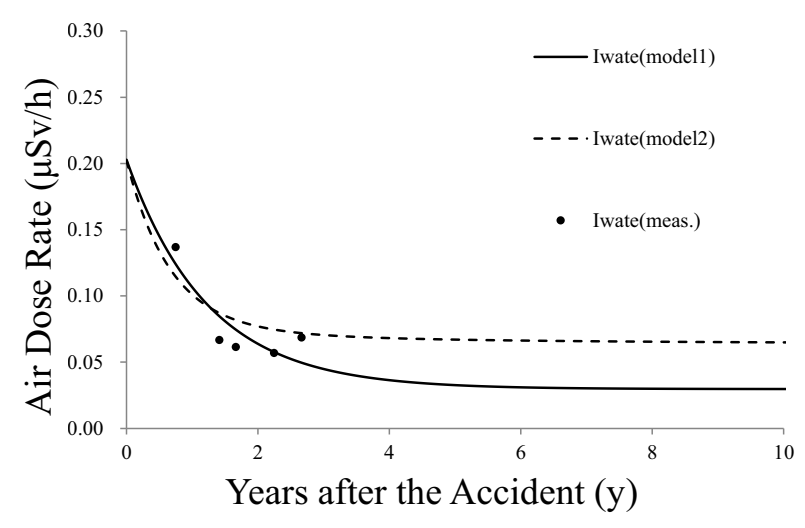

Fig. 7. Air does rate (Iwate Pref.)

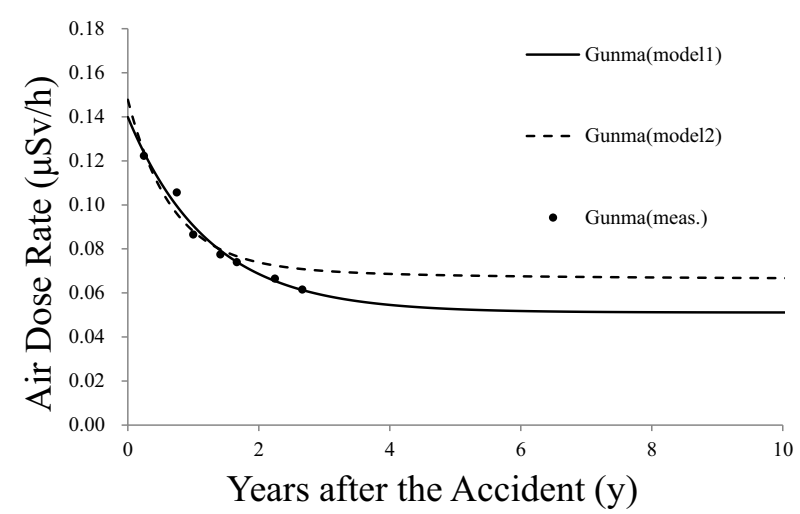

Fig. 8. Air does rate (Gunma Pref.) 


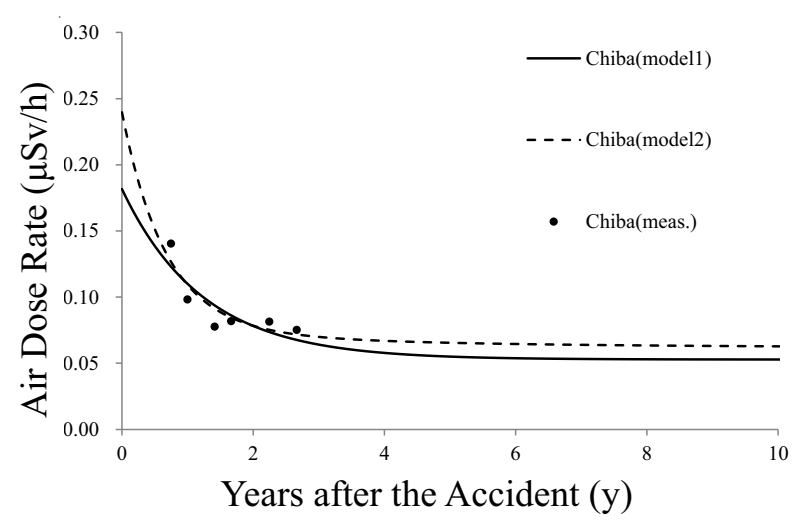

Fig. 9. Air does rate (Chiba Pref.)

\subsection{Effective dose (considering ${ }^{137} \mathrm{Cs}$ and ${ }^{134} \mathrm{Cs}$ )}

Based on the time-dependent degrease of air dose rate shown in 3.1, we estimated accumulated effective dose (considering only ${ }^{137} \mathrm{Cs}$ and ${ }^{134} \mathrm{Cs}$ ) by equation (3) and (4). Fig. 10 Fig. 12 show the estimated results for Miyagi Pref., Ibaraki Pref. and Tochigi Pref.

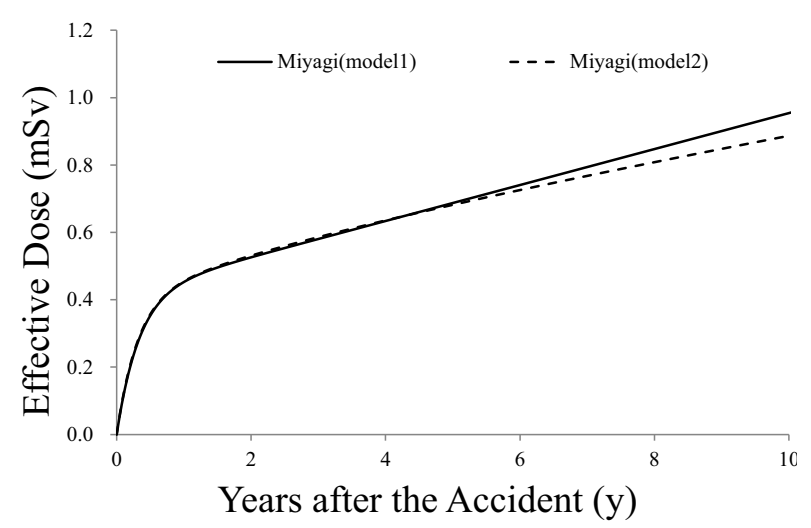

Fig. 10. Effective dose (considering ${ }^{137} \mathrm{Cs}$ and ${ }^{134} \mathrm{Cs}$ ) (Miyagi Pref.)

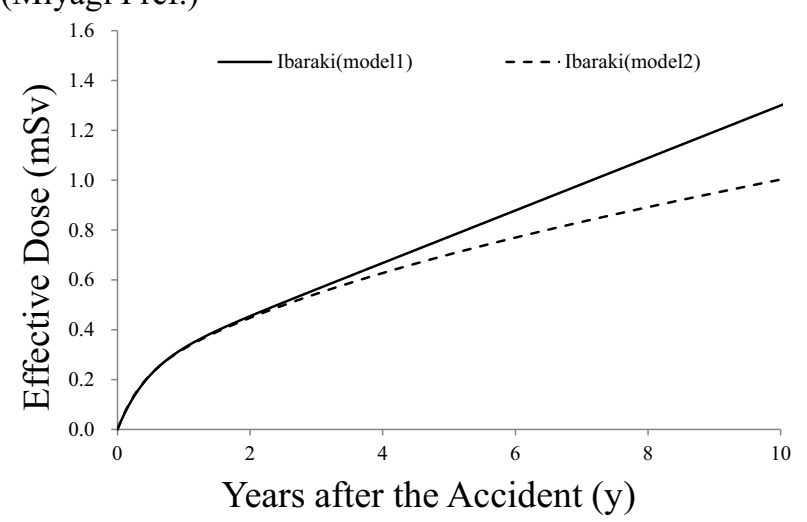

Fig. 11. Effective dose (considering ${ }^{137} \mathrm{Cs}$ and ${ }^{134} \mathrm{Cs}$ ) (Ibaraki Pref.)

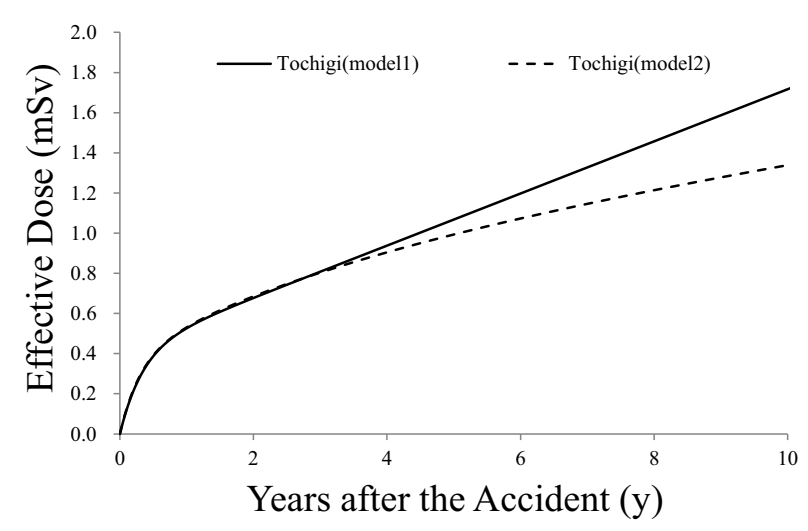

Fig. 12. Effective dose (considering ${ }^{137} \mathrm{Cs}$ and ${ }^{134} \mathrm{Cs}$ ) (Tochigi Pref.)

For the three prefectures where some parameters were fixed with the values determined in the other prefecture or fixed with the typical value, the estimated results are shown in Fig. 13 Fig. 15. For the first model in Iwate Pref. and Gunma Pref., air dose rate decreases to the background level. In this case, when integrateing by equation (4), interval of integration was confined till air dose rate gets the background level.

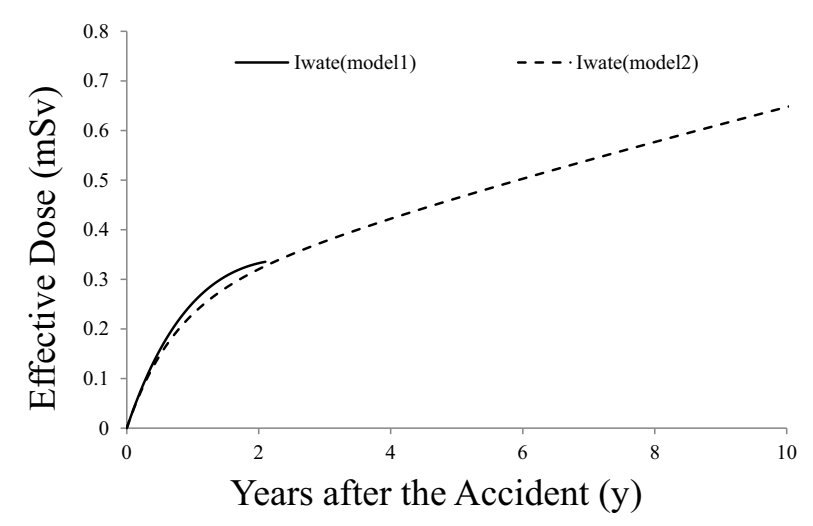

Fig. 13. Effective dose (considering ${ }^{137} \mathrm{Cs}$ and ${ }^{134} \mathrm{Cs}$ ) (Iwate Pref.)

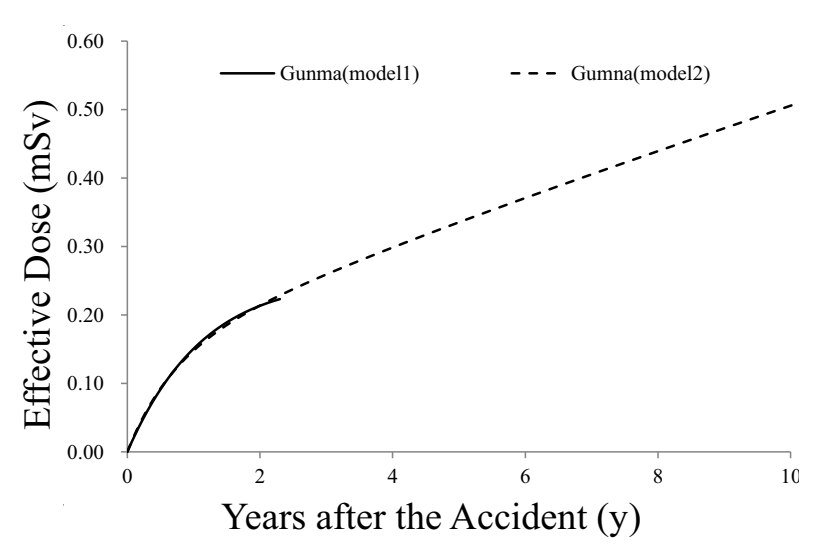

Fig. 14. Effective dose (considering ${ }^{137} \mathrm{Cs}$ and ${ }^{134} \mathrm{Cs}$ ) (Gunma Pref.) 


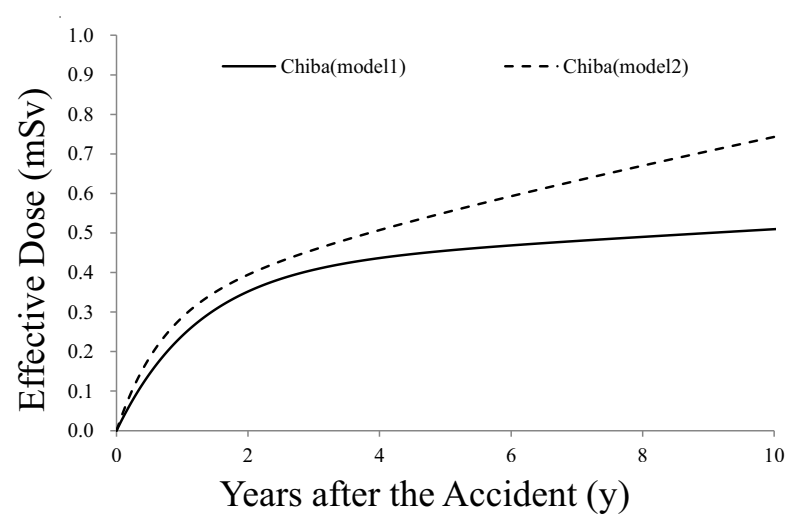

Fig. 15. Effective dose (considering ${ }^{137} \mathrm{Cs}$ and ${ }^{134} \mathrm{Cs}$ ) (Chiba Pref.)

3.3 Effective dose (considering ${ }^{137} \mathrm{Cs},{ }^{134} \mathrm{Cs}$ and shorthalf-life nuclides)

The results shown in 3.2 do not include the contribution from short-half-life nuclides. By the method shown in 2.3, we also estimated accumulated effective dose considering short-half-life nuclides.

Estimation was conducted under the condition below.

- Only some prefectures (Miyagi Pref., Ibraki Pref. and Tochigi Pref.) were targeted.

- The interval of integration ranges from $T_{1}=0 \mathrm{y}$ to $T_{2}=3 \mathrm{y}$, because half-lives of other nuclides than ${ }^{137} \mathrm{Cs}$ and ${ }^{134} \mathrm{Cs}$ are relatively short (a few ten days at longest)

- The fast model was used because in this range, there is no significant deference between two models.

The estimated results are shown in Fig. 16 Fig. 18.

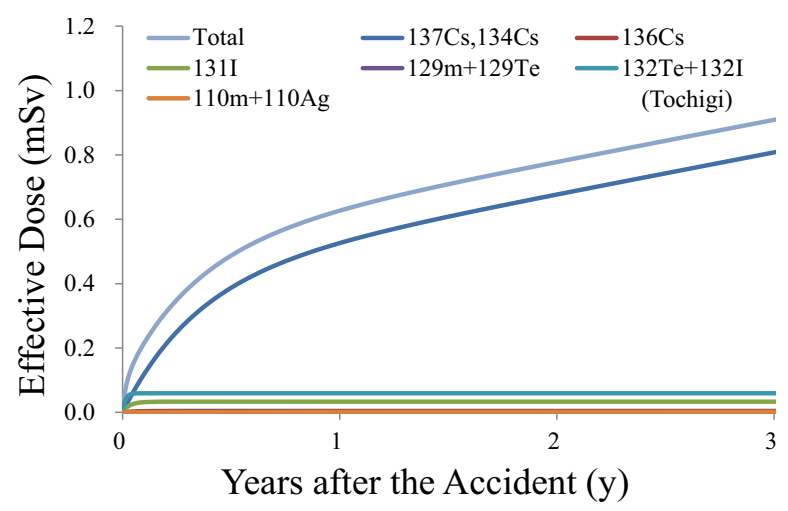

Fig. 16. Effective dose (considering ${ }^{137} \mathrm{Cs},{ }^{134} \mathrm{Cs}$ and short-half-life nuclides) (Tochigi Pref.)

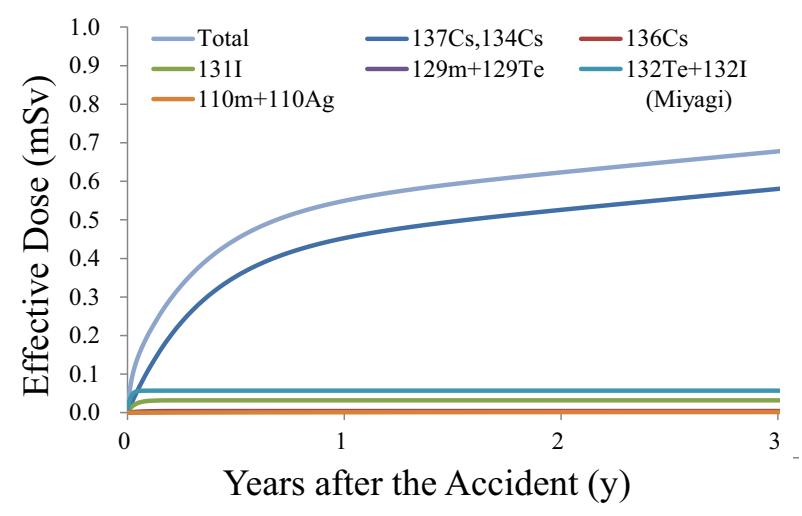

Fig. 17. Effective dose (considering ${ }^{137} \mathrm{Cs},{ }^{134} \mathrm{Cs}$ and short-half-life nuclides) (Miyagi Pref.)

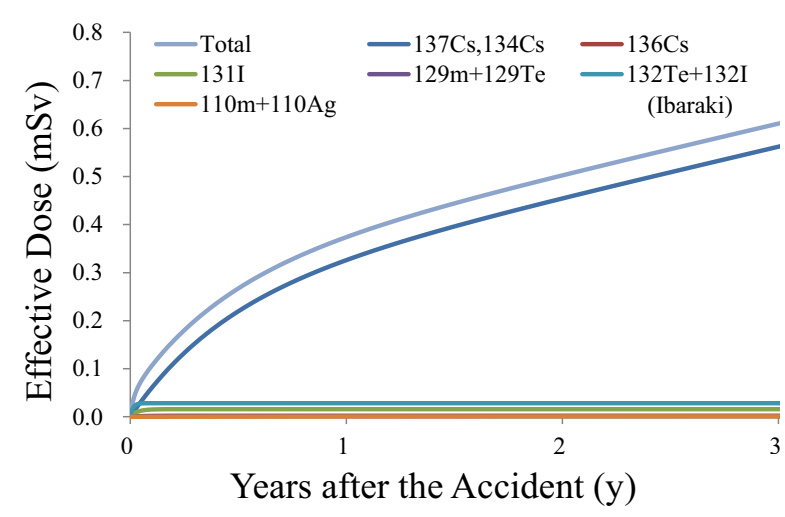

Fig. 18. Effective dose (considering ${ }^{137} \mathrm{Cs},{ }^{134} \mathrm{Cs}$ and short-half-life nuclides) (Ibaraki Pref.)

3.4 Estimation in Marumori Town in Miyagi Pref.

As shown in 1., there were some cases where measurement using personal dosimeters were conducted. In particular, in Marumori Town in Miyagi Pref., measurement had been conducted for relatively long [6]. In order to compare results, we estimated effective dose in this town.

First, we analysed averaged measured date of air dose rate in this town as the same way shown above, however here we used the first model here.

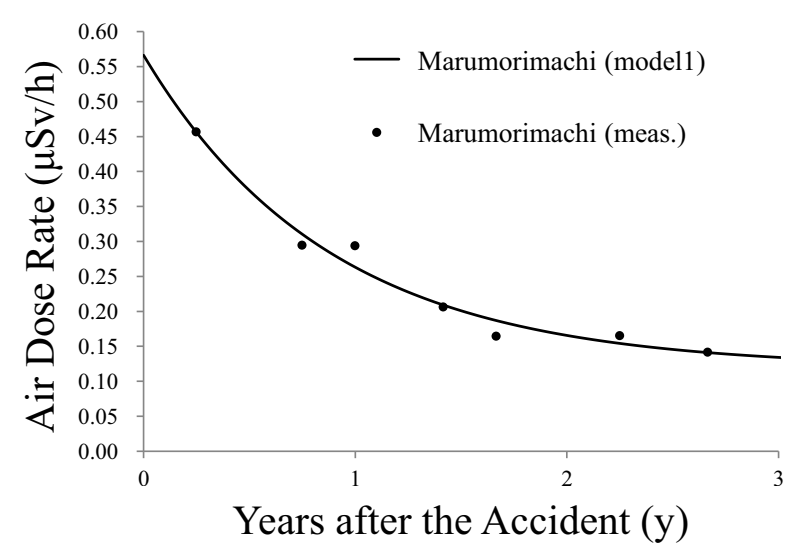

Fig. 19. Air does rate (Marumori Town in Miyagi Pref.)

Estimation of effective dose based on air dose rate was done almost the same way above exept for some small changes below. 
- Distributions of parameters were considered as possible, and ten thouthands sets of randam numbers of the distributions were generated.

- Conversion factor was changed, because examinees in Marumori Town were children.

- Background was not sabstructed in equation (3) because accumulated value by personal dosimeters includes background.

- Interval of integration $\left(T_{1}, T_{2}\right)$ in equation (4) was changed to adjust to the condition of measurement using personal dosimeters in Marumori Town.

The parameters used here are listed in Table. 11.

Table. 11. Parameters used in estimation for Marumori Town in Miyagi Pref.

\begin{tabular}{|c|c|c|c|}
\hline \multicolumn{2}{|c|}{ Parameters } & Value & Ref. \\
\hline$p$ & $\begin{array}{c}\text { Lognormal } \\
\text { distribution }\end{array}$ & Mode $: 1.2$ & {$[10]$} \\
\hline$D_{\mathrm{BG}}$ & - & - & - \\
\hline$s$ & $\begin{array}{c}\text { Uniform } \\
\text { distribution }\end{array}$ & $\begin{array}{c}\text { Lower limit }: 0.4 \\
\text { Upper limit }: 1.0\end{array}$ & {$[7]$} \\
\hline$T_{\text {out }}$ & $\begin{array}{c}\text { Nomal } \\
\text { distribution }\end{array}$ & $\begin{array}{c}\text { Average }: 3.0 \mathrm{~h} / \mathrm{d}, \\
\text { SD }: 1.5 \mathrm{~h} / \mathrm{d}\end{array}$ & {$[6]$} \\
\hline$\alpha$ & Constan & $365 \mathrm{~h} / \mathrm{d}$ & - \\
\hline$f$ & Constant & 0.7 & {$[17]$} \\
\hline
\end{tabular}

Estimated results are shown in Fig. 20 Fig. 22. The values written in these figures with dashed lines are the typical value measured with personal dosimeter in each area in Marumori Town (Table. 1) [6].

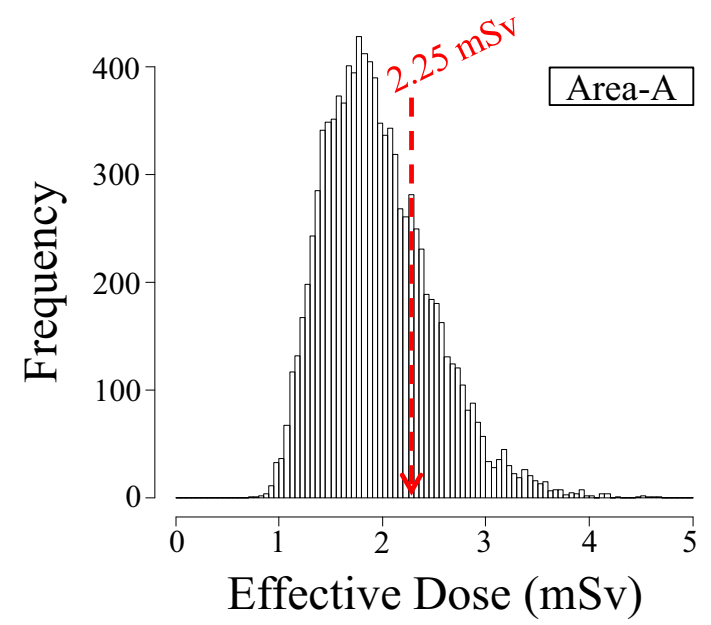

Fig. 20. Distribution of estimated effective dose including background in area A in Marumori Town (the value $2.25 \mathrm{mSv}$ is the typical one measured in this area)

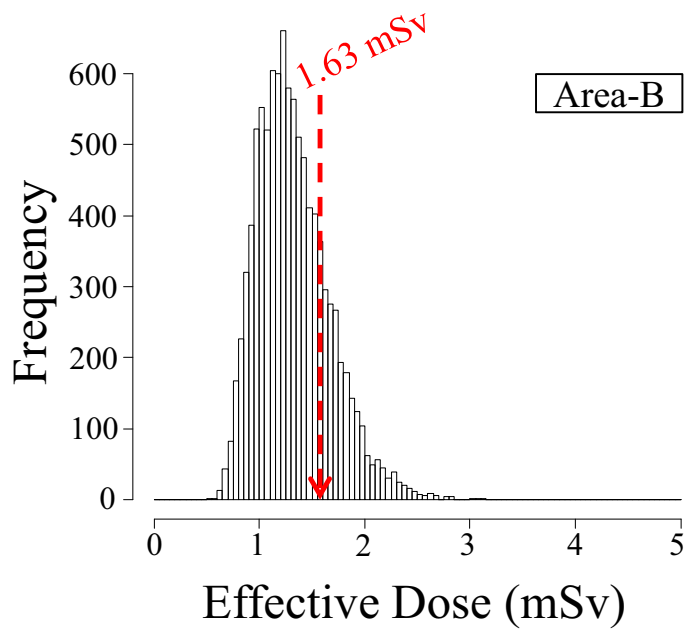

Fig. 21. Distribution of estimated effective dose including background in area B in Marumori Town (the value $1.63 \mathrm{mSv}$ is the typical one measured in this area)

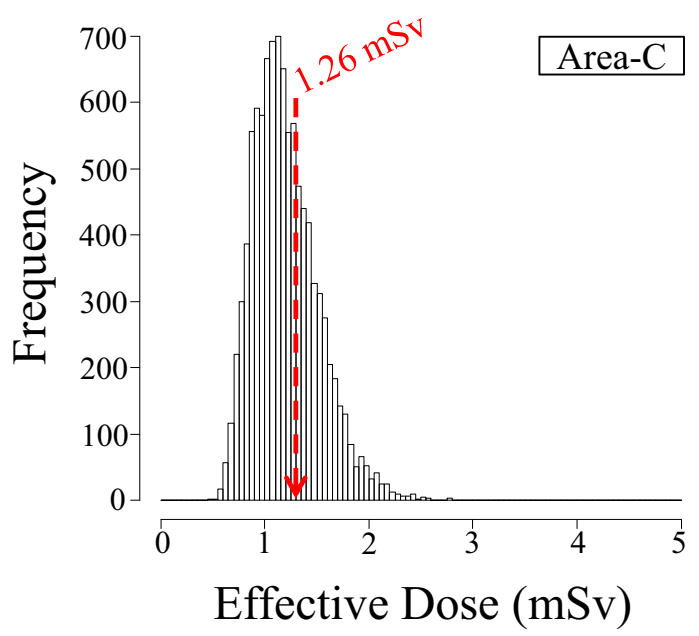

Fig. 22. Distribution of estimated effective dose including background in area $\mathrm{C}$ in Marumori Town (the value $1.26 \mathrm{mSv}$ is the typical one measured in this area)

\section{Discussions}

\subsection{Comparison with estimation of UNSCEAR}

Estimated effective dose in this study and that of UNSCEAR are listed in Table. 12. In this list, these values does not include background. Although UNSCEAR estimated at the level of cities, towns and villages, in this study we estimated at the level of prefectures. Therefore, estimated values of UNSCEAR were shown minimum and maximum values given by cities, towns or villages belonging to each prefecture.

[18][19]. 
Table. 12. Comparison of estimated results (mSv)

\begin{tabular}{|c|c|c|c|c|c|}
\hline \multirow{2}{*}{} & \multicolumn{3}{|c|}{ This study } & \multicolumn{2}{c|}{ UNSCEAR } \\
\cline { 2 - 5 } & model & $1 \mathrm{y}$. & $10 \mathrm{y}$. & $1 \mathrm{y}$. & $10 \mathrm{y}$. \\
\hline Iwate & model1 & 0.25 & - & 0.14 & 0.1 \\
\cline { 2 - 4 } Pref. & model2 & 0.23 & 0.65 & $\sim 0.31$ & $\sim 0.7$ \\
\hline Miyagi & model1 & 0.45 & 0.95 & 0.05 & 0.1 \\
Pref. & model2 & 0.45 & 0.89 & $\sim 0.55$ & $\sim 1.3$ \\
\hline Ibaraki & model1 & 0.33 & 1.30 & 0.06 & 0.1 \\
Pref. & model2 & 0.32 & 1.00 & $\sim 0.54$ & $\sim 1.3$ \\
\hline Tochigi & model1 & 0.53 & 1.72 & 0.06 & 0.2 \\
Pref. & model2 & 0.53 & 1.34 & $\sim 1.07$ & $\sim 2.5$ \\
\hline Gunma & model1 & 0.15 & - & 0.06 & 0.1 \\
\cline { 2 - 4 } Pref. & model2 & 0.15 & 0.51 & $\sim 0.50$ & $\sim 1.2$ \\
\hline Chiba & model1 & 0.24 & 0.51 & 0.05 & 0.1 \\
\cline { 2 - 4 } Pref. & model2 & 0.29 & 0.74 & $\sim 0.76$ & $\sim 1.8$ \\
\hline
\end{tabular}

Table. 12 shows that the values we estimated are witin the range of those of UNSCEAR. However, it is necessary to see the maximum value given by estimation of UNSCEAR, because of the differnece of geographical unit for estimeation. The maximum values in Table. 12 are $1.07 \mathrm{mSv}$ (for 1y. in Tochigi Pref.) and $2.5 \mathrm{mSv}$ (for $10 \mathrm{y}$. in Tochigi Pref.). Tese values are given by Nasu Town in Tochigi Prefecture [18][19].

We estimated efective dose in Nasu Town by the same way as shown above. The resulut is shown in Fig. 23. In this figure, in order to compare with the estimation of UNSCEAR, the curve of UNSCEAR estimation that we calucurated based on the medhod of UNSCEAR in this study is also shown [15].

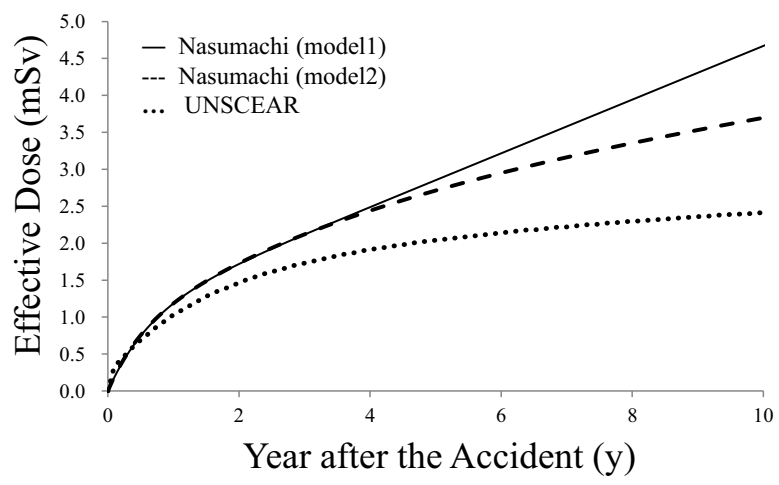

Fig. 23. Effective dose (Nasu Town in Tochigi Pref.)

Fig. 23shows that within a year after the accident the estimated values of both are almost same, however the longer time passes, the larger the estimated value in this study get.

In the UNSCEAR method, measured deposition density was used for input data. This measurement was conducted only one time within a few months after the accident. The number of measurement points was quite fewer than that of car-borne survey. In addition, some parameters used in UNSCEAR method are based on Chernobyl accident, therefore it is possible that environmental characteristics in Japan are not reflected enough.

\subsection{Contribution from short-half-life nuclides}

Fig. 24 shows the ratio of contribution from effective dose each nuclides to the total.

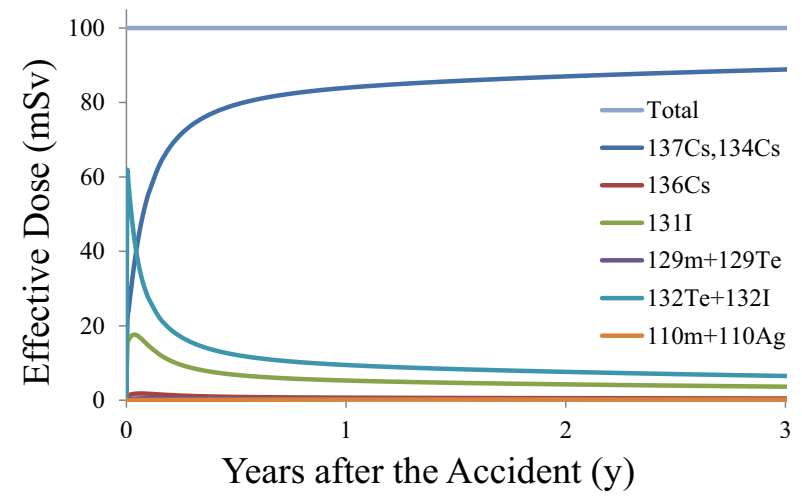

Fig. 24. Contribution from each nuclide to effective dose

This graph shows that within a few months after the accident the contribution from ${ }^{132} \mathrm{Te},{ }^{132} \mathrm{I}$ and ${ }^{131} \mathrm{I}$ is relatively large, and the contribution from ${ }^{137} \mathrm{Cs}$ and ${ }^{134} \mathrm{Cs}$ gets more dominant as time passes. At three years after the accident, the ratio of ${ }^{137} \mathrm{Cs}$ and ${ }^{134} \mathrm{Cs}$ to the total exceeds 80 percent. This suggests that estimated effective dose considering not only ${ }^{137} \mathrm{Cs}$ and ${ }^{134} \mathrm{Cs}$ but also other short-half-life nuclides is about 1.2 times larger than the one considering only ${ }^{137} \mathrm{Cs}$ and ${ }^{134} \mathrm{Cs}$.

\subsection{Comparison with measurement using personal dosimeters}

Estimating effective dose in Marumori Town in Miyagi Pref., we considered distribution for some parameters. Therefore estimated value also has its distribution. Comparing the distributions of estimated value with typical measured value using personal dosimeters for three cases, it is shown that the latter value is within the distribution and corresponds to about 1.2 to 1.3 times lager value than the mode of each distribution. Although the distribution and typical measured values are in good agreement, it is necessary to be aware that they are basically different. There are some assumptions and some conversion factors that have uncertainty behind estimated values, although measured values using personal dosimeters are reflected by real behavioural pattern of each examinee.

\section{REFERENCES}

1. JAEA, Report in Japanese (2016), pp 102-119 http://radioactivity.nsr.go.jp/ja/list/564/list-1.html

2. JAEA, Database for Radioactive Substance Monitoring Data, http://emdb.jaea.go.jp/emdb/

3. UNSCEAR, UNSCEAR 2013 Report Volume 1 (2013)

4. Report written in Japanes, http://www.pref.tochigi.lg.jp/e04/documents/docum ents/documents/report.pdf

5. T. Iimoto et al., Measures of a Local Government in Tokyo Metropolitan Area on Environmental Radioactive Conteamination due to Fukushima Dai-ichi Nuclear Power Plant Accident and Related 
Discussion, Radiation Biology Research Communications 48 (1), pp. 15-38 (2013)

6. H. Yoshida et al., Survey Report on Personal Dose Equivalent and Indoor and Outdoor Staying Time for Children in the Southern Miyagi Prefecture after the Fukushima Daiichi Nuclear Power Plant Accident, RADIOISOTOPES Vol. 64 No. 5, pp. 319-333 (2015)

7. H. Yoshida et al., Effect of Shieldings on Ambient Equivalent Dose Rate Reduction Inside Resident's House after the Fukushima Daiichi Nuclear Power Plant Accident, RADIOISOTOPES Vol. 62 No. 4, pp. 203-210 (2013)

8. JAEA, Report in Japanese (2016), http://radioactivity.nsr.go.jp/ja/contents/12000/119 95/33/part2.pdf

9. H.J.Gale, D.L.O.Humphreys and E.M.R.Fisher, Weathering of Caesium-137 of soil, Nature, 4916, 257-261 (1964)

10. JAEA, Report in Japanese (2014), http://radioactivity.nsr.go.jp/ja/list/504/list-1.html

11. The Japan Chemical Analysis Center, Environmental Radioactivity and Radiation in Japan, http://www.kankyohoshano.go.jp/study_menu.html

12. Takahara, S., Iijima M., Shimada K., Kimura M. and Homma T., Probabilistic Assessment of Doses to the Public Living in Areas Contaminated by the Fukushima Daiichi Nuclear Power Plant Accident, Radiation Monitoring and Dose Estimation of the Fukushima Nuclear Accident, pp. 197-214 (2014)

13. IAEA, Generic procedures for assessment and response during a radiological emergency, IAEATECDOC-1162, pp.1-181 (2000)

14. ICRP, Conversion Coefficients for use in Radiological Protection against External Radiation, ICRP Publication 74, Ann. ICRP 26 pp.3-4 (1996)

15. UNSCEAR, METHODOLOGY FOR THE ASSESSMENT OF DOSE FROM EXTERNAL EXPOSURE AND INHALATION OF RADIOACTIVE MATERIAL, UNSCEAR 2013 Report, ATTACHMENT C-12 (2013)

16. Saito K, Ambient dose equivalent conversion coefficients for radionuclides exponentially distributed in the ground, Journal of Nuclear Science and Technology, 51, pp. 1274-1287(2014)

17. K. Akahane et al., NIRS external dose estimation system for Fukushima residents after the Fukushima Dai-ichi NPP accident., Sci Rep. 2013;3 pp.1670 (2013)

18. UNSCEAR, EFFECTIVE DOSES IN JAPAN FOR THE FIRST YEAR, UNSCEAR 2013 Report, ATTACHMENT C-14 (2013)

19. UNSCEAR, TOTAL EFFECTIVE DOSES IN JAPAN FOR 10-YEAR AND LIFETIME EXPOSURE, UNSCEAR 2013 Report, ATTACHMENT C-19 (2013) 